\title{
A RELAÇÃO ENTRE REGIME DEMOCRÁTICO E DIREITO À INFORMAÇÃO
}

\author{
ALEXANDRE COUTINHO PAGLIARINI ${ }^{*}$ \\ LEONARDO CESAR DE AGOSTINI**
}

RESUMO: Estabelece o presente texto uma relação entre democracia e direito à informação nas sociedades livres e na comunidade internacional, fator este que se garante por meio da positivação de Constituições, Tratados Internacionais e Textos Legais, chegando-se à conclusão de que não há democracia se não estiver concomitantemente garantido o livre acesso de todos aos meios de comunicação.

PALAVRAS-CHAVE: Democracia. Direito à Informação. Constituição. Tratados Internacionais. Diplomas Legais. Relação entre Democracia e Informação.

ABSTRACT: Stabilishes this text a relation betwen democracy and right of information in the free societies ad in the international community. The garanty for that exists by the positivation of Constitutions, International Treaties and Legal Texts and the conclusion of the present study is that there is no democracy without the right of access to all means of communication.

KEYWORDS: Democracy. Right of Information. Constitution. International Treaties. Legal Texts. Relation between Democracy and Information.

SUMÁRIO: 1. Introdução. 2. A comunicação, a informação e o direito à informação. 3. A democracia. 4. A estreita ligação entre democracia e o direito fundamental à informação. 5. Considerações finais; 6 . Referências.

SUMMARY: 1. Introduction; 2. Communication, information and the right to information; 3. Democracy; 4 . The close connection between democracy and the fundamental right to information; 5. Final Remarks; 6. Referências.

\section{INTRODUÇÃO}

Duas temáticas ocupam o pensamento dos mais variados estudiosos das ciências humanas e sociais: a informação e a democracia, as quais estão fortemente

Artigo recebido em 15.03.2009 e aprovado para publicação pelo Conselho Editorial em 14.10.2009.

* Pós-Doutor em Direito pela Universidade de Lisboa. Doutor e Mestre pela PUC/SP. Professor da FACINTER, da OPET e da UniBrasil. Professor nas Pós-Graduações do CEU (Centro de Extensão Universitária/SP) e da ABDConst (Academia Brasileira de Direito Constitucional). Professor-Visitante no Programa de Mestrado da UFAL (Universidade Federal de Alagoas) e Professor-Assistente na Faculdade de Direito da Universidade de Lisboa (Substituto do Catedrático Jorge Miranda). Colaborador do IBEC (Instituto Brasileiro de Estudos Constitucionais). Advogado.

${ }^{* *}$ Mestrando em Direito Constitucional pela UNIBRASIL; Professor Universitário; Advogado Militante; Membro do Corpo Editorial da Revista Direitos Fundamentais e Democracia. 
ligadas como verdadeiras "irmãs siamesas". ${ }^{1}$ Assim, se uma delas é valorizada, a outra se fortalece. Por outro lado, se uma delas sofre ataque, a outra enfraquece.

Exemplo recente que prova a conexão entre informação e democracia foi o episódio do fechamento de rede de televisão na Venezuela ${ }^{2}$, oportunidade em que a conduta do governo foi alvo de protestos da comunidade internacional e da população daquele país ${ }^{3}$, pois se entendeu que atitude assim colocaria em risco o pleno desenvolvimento da democracia.

\section{A COMUNICAÇÃO, A INFORMAÇÃO E O DIREITO À INFORMAÇÃO}

Para George GERBNER, a comunicação é o elemento mais "humanizador” de nossa espécie. ${ }^{4}$ É por meio deste elemento (comunicação) que os indivíduos criam e recriam símbolos de aspectos da condição humana que podem ser apreendidos por terceiros fomentando a agregação das pessoas e das comunidades. Compreende GERBNER que

"somente o cérebro humanóide poderia regular o organismo, responder ao meio ambiente imediato e ainda manter a capacidade de manter a capacidade de reserva mecânica necessárias para reter uma imagem tempo bastante para reflexionar sobre ela, registrá-la, guardá-la e restaurá-la, sob a forma de mensagens." 5

A comunicação é um processo e a forma mais visível desse processo é o seu verdadeiro objeto, qual seja a informação. ${ }^{6}$

É por meio da informação que o ser humano constrói toda a sua personalidade. Dessa forma, informação e formação estão estritamente relacionadas ${ }^{7}$. À medida que o saber determina o entendimento e as opções da consciência, distingue os seres inteligentes de todas as demais espécies que exercitam o dom da vida. ${ }^{8}$

\footnotetext{
${ }^{1}$ A expressão é do Ministro do Supremo Tribunal Federal Carlos Ayres Brito na decisão proferida na medida cautelar em argüição de descumprimento de preceito fundamental (ADPF) n ${ }^{\circ}$ 130-7, de 21.02.2008.

${ }^{2} \mathrm{O}$ fechamento foi determinado pelo presidente da Venezuela. A emissora afetada foi a Rede de Televisão RCTV, que transmitia ininterruptamente por 53 anos e foi acusada pelo chefe do Executivo venezuelano de ter apoiado golpe de estado contra ele no ano de 2002

${ }^{3}$ Acessível em: http://noticias.uol.com.br/ultnot/afp/2007/05/26/ult34u181742.jhtm Capturado em 02.03.2008 às $14 \mathrm{~h} 44 \mathrm{~min}$.

${ }^{4}$ GERBNER, George. Os meios de comunicação de massa e a teoria da comunicação humana. In Teoria da comunicação humana. Org.: Frank E. X. Dance. São Paulo: Editora Cultrix, 1967. p. 57.

${ }^{6}$ Para José Marques de Melo a comunicação constitui um processo de que a informação é um dos elementos. Entretanto, para o mesmo autor a informação é o "elemento fundamental” deste processo, pois ela é o objeto da comunicação; é o conteúdo a ser comunicado. Explica Melo que se duas pessoas se comunicam, não o fazem por fazer, elas têm um objetivo claro: o de realizar intercâmbio de informações, daí porque é lícito afirmar que a comunicação pressupõe a informação. Ou melhor, sem informação não há comunicação. (in Teoria da comunicação: paradigmas latino-americanos. Petrópolis: Editora Vozes, 1998. p. 60.)

${ }^{7}$ PERLINGIERI, Pietro. Perfis do Direito Civil - introdução ao Direito Civil Constitucional. Tradução de Maria Cristina De Cicco. São Paulo: Renovar, 1999. p. 193.

${ }^{8}$ CASTRO, Carlos Roberto Siqueira. A Constituição aberta e os direitos fundamentais - ensaio sobre o constitucionalismo pós-moderno e comunitário. Rio de Janeiro: Forense, 2005. p. 437.
} 
Há de se considerar, igualmente, a essencialidade da informação para o exercício da liberdade; é por seu intermédio que o ser humano constrói um espaço de liberdade. Daí porque temos o direito constitucional de pensar, de falar, de publicar, de nos expressarmos artisticamente, confirmando-se tais prerrogativas como fundamentais ao exercício da liberdade. Se um indivíduo se vê obrigado a guardar silêncio e permanecer inerte, por certo e invariavelmente tende a se converter em ser "torpe $e$ 'incoherente ",9. O homem deixa de ser um fim para se transformar em um instrumento para atingir os objetivos de outras pessoas.

Há mecanismos normativos internacionais, constitucionais e legais que resguardam o direito à informação. A Declaração Universal dos Direitos Humanos (ONU) prevê expressamente os direitos às liberdades de expressão e de comunicação. No mesmo sentido, o Convênio Europeu para a Proteção dos Direitos Humanos e Liberdades fundamentais (Roma, 1950), que instituiu a proteção às liberdades de expressão e de comunicação. Ainda, o Pacto de Direitos Civis e Políticos de 1966; a Convenção Americana de Direitos Humanos, de 1969; assim como a Declaração dos Princípios Fundamentais Relativos ao Fortalecimento da Paz e da Compreensão Internacional, à Promoção dos Direitos Humanos e à Luta contra o Racismo e a Apartheid, e a limitação à guerra, proclamada em $1978^{10}$.

No âmbito das Constituições contemporâneas, não foi diferente. Como exemplos, consideremos a Carta espanhola (que assegurou a livre difusão de idéias em seu artigo $20^{11}$ ); a Constituição Chilena, de 1980 (item 12, artigo $19^{12}$ ); e a da

${ }^{9}$ LASKI, Harold J. La libertad en el Estado moderno. Buenos Aires: Editorial Abril, 1945. p. 67.

${ }^{10}$ ALMAZÁN, Jaime. Derecho a la Información y Derechos Humanos. Acessível em http://www.itaipem.org.mx/ work/resources/LocalContent/379/3/X\%20mesa\%20Derecho\%20info\%20jaime\%20almazan\%20ok.doc.

Capturado em 02.07.2007 às $10 \mathrm{~h} 47 \mathrm{~min}$.

${ }^{11}$ Artículo 20.

1. Se reconocen y protegen los derechos:

a) A expresar y difundir libremente los pensamientos, ideas y opiniones mediante la palabra, el escrito o cualquier otro medio de reproducción.

b) A la producción y creación literaria, artística, científica y técnica.

c) A la libertad de cátedra.

d) A comunicar o recibir libremente información veraz por cualquier medio de difusión. La ley regulará el derecho a la cláusula de conciencia y al secreto profesional en el ejercicio de estas libertades.

2. El ejercicio de estos derechos no puede restringirse mediante ningún tipo de censura previa.

3. La ley regulará la organización y el control parlamentario de los medios de comunicación social dependientes del Estado o de cualquier ente público y garantizará el acceso a dichos medios de los grupos sociales y políticos significativos, respetando el pluralismo de la sociedad y de las diversas lenguas de España. 4. Estas libertades tienen su limite en el respeto a los derechos reconocidos en este Titulo, en los preceptos de las leyes que lo desarrollan y, especialmente, en el derecho al honor, a la intimidad, a la propia imagen y a la protección de la juventud y de la infancia.

5. Sólo podrá acordarse el secuestro de publicaciones, grabaciones y otros medios de información en virtud de resolución judicial.

${ }^{12}$ Conteúdo de mencionada disposição:

“12. La libertad de emitir opinión y la de informar, sin censura previa, en cualquier forma y por cualquier medio, sin perjuicio de responder de los delitos y abusos que se cometan en el ejercicio de estas libertades, en conformidad a la ley, la que deberá ser de quórum calificado. La ley en ningún caso podrá establecer monopolio estatal sobre los medios de comunicación social. Toda persona natural o jurídica ofendida o injustamente aludida por algún medio de comunicación social tiene derecho a que su declaración o rectificación sea gratuitamente difundida, en las condiciones que la ley determine, por el medio de 
Argentina (artigo 14, capítulo primeiro ${ }^{13}$ ). Pode-se afirmar que as Cartas políticas contemporâneas dos países ocidentais e democráticos seguiram a opção política internacional constante nos tratados firmados após a Segunda Guerra Mundial, os quais se preocuparam em assegurar expressamente a liberdade de informação e o livre fluxo de idéias como liberdades fundamentais dos cidadãos.

No Brasil, a Carta Magna em vigor estimulou o direito à informação, senão vejamos: liberdade de comunicação (art. $5^{\circ}$, IV e IX); acesso à informação (art. $5^{\circ}$, XIV); comunicação social (arts. 220 a 224). No capítulo dedicado à comunicação social, a Constituição determinou que as atividades de divulgação de informações "não sofrerão qualquer restrição” (art. 220, caput) a não ser aquelas previstas na própria Constituição.

\section{A DEMOCRACIA}

Apesar da aparente facilidade em se afirmar o que seria democracia, o certo é que nenhum termo do vocabulário político é mais controverso do que este ${ }^{14}$.

Ao abordar-se determinado cidadão comum e indagá-lo sobre o que o mesmo entende por democracia, constatar-se-á, provavelmente, que a sua percepção de democracia esteja automaticamente conectada a forma de governo "do povo, pelo povo e para o povo" ${ }^{\text {"15 }}$. A expressão consagrada por Lincoln merece reparos uma vez que pelo povo e para o povo são instigantes de um pensamento que possa pressupor que haja uma instância maior do que o próprio povo na condução dos assuntos da Polis (e também, hoje, da Cosmópolis).

Ademais, democracia não é só o que disse o presidente norte-americano. Democracia é mais do que simplesmente uma forma de governo ou um regime político. É mais do que exercer o direito ao voto. É mais do que assegurar formalmente direitos fundamentais. Democracia é um conceito múltiplo e variável ${ }^{16}$

comunicación social en que esa información hubiera sid o emitida. Toda persona natural o jurídica tiene el derecho de fundar, editar y mantener díarios, revistas y periódicos, en las condiciones que señale la ley. El Estado, aquellas universidades y demás personas o entidades que la ley determine, podrán establecer, operar y mantener estaciones de televisión. Habrá un Consejo Nacional de Televisión, autónomo y con personali dad jurídica, encargado de velar por el correcto funcionamiento de estos medios de comunicación. Una ley de quórum calificado señalará la organización y demás funciones y atribuciones del referido Consejo. La ley establecerá un sistema de censura para la exhibición y publicidad de la producción cinematográfica;”

13 “Artículo 14.- Todos los habitantes de la Nación gozan de los siguientes derechos conforme a las leyes que reglamenten su ejercicio; a saber: de trabajar y ejercer toda industria lícita; de navegar y comerciar; de peticionar a las autoridades; de entrar, permanecer, transitar y salir del territorio argentino; de publicar sus ideas por la prensa sin censura previa; de usar y disponer de su propiedad; de asociarse con fines útiles; de profesar libremente su culto; de enseñar y aprender.” (grifo nosso)

${ }^{14}$ HESSE, Konrad. Elementos de Direito Constitucional da República Federal da Alemanha - (Grundzüge des Verfassungsrechts der Bundesrepublik Deutschland). Tradução de Luís Afonso Heck. Porto Alegre: Sérgio Fabris, 1998, p. 115. MÜLLER, Friedrich. Democracia e República. http://www.presidencia.gov.br/ ccivil_03/revista/Rev_77/artigos/Muller-rev77.htm

${ }^{15}$ A clássica proposição formulada por Abrahan LINCOLN, em seu discurso em Gettysburg em 1863.

${ }^{16}$ Giovanni SARTORI afirma que existem muitos motivos para que o conceito de democracia se apresente difuso e multifacetado. Primeiro, porque a democracia em geral atualmente pode ser vista como o nome de uma civilização, ou melhor, do produto final político da civilização ocidental. Da mesma forma, diferentemente do que aconteceu com o comunismo e o socialismo que tendencialmente poderiam ser conectados a um único e grande autor - Karl Marx - a democracia remonta ao pensamento de vários 
que se constrói e se aperfeiçoa com o passar dos tempos, proporcionando uma convivência harmônica entre o grupo de cidadãos que compõe um Estado.

Acompanhando a doutrina acerca da democracia, verifica-se hoje uma tendência segundo a qual o seu fulcro maior reside na abertura para que fluam idéias num processo comunicativo na sociedade de informação formada pelo povo. Deste modo, onde não há diálogo, sequer se pensa em democracia. É por isso que Gustavo BINENBOJM afirmou que a maior arma de uma ditadura não é o tanque ou o canhão, mas sim a censura ${ }^{17}$.

O alargamento dos mecanismos de participação popular direta (democracia popular) também é levado em conta como forma de amenizar as mazelas da democracia representativa contemporânea.

4. A ESTREITA LIGAÇÃO ENTRE DEMOCRACIA E O DIREITO FUNDAMENTAL À INFORMAÇÃO

Carlos Ayres BRITTO, em voto no Supremo Tribunal Federal brasileiro, declarou que a informação e a democracia podem ser vistas como "irmãs siamesas" dada a sua estreita ligação. ${ }^{18}$ Indubitavelmente, sem liberdade de expressão e direito à informação não há verdadeira democracia, pois a livre circulação de ideias é pressuposto do governo do povo. Acerca disso há antecedentes no Direito Internacional: em julgado do Tribunal Europeu de Direitos Humanos, a liberdade de expressão e de informação se constitui em um dos fundamentos essenciais para a constituição de uma sociedade democrática, pois a liberdade de informação e de expressão proporciona o progresso e o desenvolvimento dos homens. ${ }^{19}$

Como se sabe, uma sociedade democrática se funda na idéia de que os governados formam uma “joint venture"20. Assim, a sociedade legitimamente democrática somente se constrói se nela for assegurada plenamente a liberdade de expressão e de informação. Nas palavras de Artemi Rallo LOMBARTE, "la calidad del régimen democrático se halla en relación directamente proporcional a la calidad informativa de sus ciudadanos; y el tratamiento que merece el derecho a comunicar y a recibir información gradúa la intensidad democrática del régimen político. „21

autores, iniciando-se com Aristóteles e Platão na Grécia Antiga, e chegando a Modernidade a idéia de democracia é bem diferente daquela inicialmente delineada. In A teoria da democracia revisitada - volume I - o debate contemporâneo. Trad. de Dinah de Abreu Azevedo. São Paulo: Ática, 1994. pp. 17-18.

${ }^{17}$ Toda ditadura se mantém pela força. Tanques e canhões, todavia, não são suas armas principais. É que se a força bruta impede que novas idéias ascendam ao poder, a censura e o controle do discurso público pelo governo impedem o seu surgimento e divulgação. Como na metáfora de George Orwell, o pior regime totalitários não almeja apenas o controle das ações na sociedade, mas do que pensam seus cidadãos.” (in Meios de comunicação de massa, pluralismo e democracia deliberativa.As liberdades de expressão e de imprensa nos Estados Unidos e no Brasil. Revista Brasileira de Direito Público. Belo Horizonte, n. 9, pp. 191-211. abr./jun 2005)

${ }^{18}$ Medida cautelar na (APDF) argüição de descumprimento de preceito fundamental n. 130-7, 21.02.2008.

${ }^{19}$ Caso Handyside versus Reino Unido, de 7 de dezembro de 1976.

${ }^{20}$ Expressão de Robert ALEXY em: A democracia e os direitos do homem. A democracia. Org. Robert Danton e Olivier Duhamel. Trad. Clóvis Marques. Rio de Janeiro: Record, 2001. p. 160.

${ }^{21}$ LOMBARTE, A. Rallo. Pluralismo político e información. Claves de Razón Práctica, 1999, n. 96, 76-80.

DIREITOS FUNDAMENTAIS E JUSTIÇA N 8 - JUL./SET. 2009 
Não é por menos que Carlos Santiago NINO, em seu trabalho La constitucion de la democracia deliberativa ${ }^{22}$, mostrando-se adepto da tradição filosófica de John RAWLS e Jürgen HABERMAS, preocupa-se com o conteúdo da Constituição e com o crescente déficit democrático. O mesmo autor adverte que a crise da democracia não se encontra no excesso de participação dos cidadãos como alguns alegam, mas sim na apatia política destes ${ }^{23}$.

Ronald DWORKIN, em recente trabalho intitulado Is Democracy Possible Here? aponta para uma crescente falta de participação do povo americano na vida política do país, fato esse que para DWORKIN se deve, primordialmente, à falta de informação, pelo que tal autor sugere mudanças na educação contemplando educação para a política; a fundação de canais públicos de televisão para fornecer cobertura no período eleitoral; a instituição de debates; e, até mesmo, a criação de um feriado nacional, especialmente destinado ao debate político. ${ }^{24}$ Portanto, seja em sede de uma democracia deliberativa (NINO), ou de uma democracia participativa (BONAVIDES), o direito à informação é um constante aliado do regime democrático.

Miguel CARBONELL opina no sentido de que a participação de todos nas discussões políticas é pressuposto necessário para a formação daquilo que Habermas chama de racionalidade discursiva, senão vejamos:

"La posibilidad de que todas personas participen en las discusiones públicas es uno de los bienes más preciados para una sociedad, y constituye el presupuesto necesario para la construcción de una "racionalidad discursiva" (Habermas), que permita la generación de consensos y la toma de decisiones entre los componentes de los diversos grupos sociales, pero que también constituya un cauce para la expresión de los disensos, que en democracia son tan naturales (y necesarios) como los acuerdos. ${ }^{25}$

\section{CONSIDERAÇÕES FINAIS}

Com a intensificação do debate na criação de uma esfera pública de discussões políticas, constrói-se uma “democracia viva” (Friedrich MÜLLER), até porque o povo já não é mais uma “maioria calada”:

"O povo, nesse novo sentido, não é mais uma "maioria calada", que nada faz quando entrega o seu voto a cada quatro ou cinco anos. Rousseau escarneceu já há 250 anos (a exemplo da Inglaterra) essa caricatura de "povo" do estado. Infelizmente, a caricatura continuou dominante até o final do século XX.

\footnotetext{
22 NINO, Carlos Santiago. La Constitucíon de la Democracia Deliberativa. 1. ed., 1 reimp. Barcelona: Gedisa Editorial, 2003.

${ }^{23}$ Este pensamento converge para a ácida crítica de DWORKIN, que relata estar a população americana mais inclinada a assistir episódios do seriado norte-americano "The Simpsons", ou do talk show "David Letterman" do que propriamente assistir a um debate na televisão sobre problemas políticos (In: DWORKIN, Ronald. Is democracy possible here? Principles for a new political debate. Princeton and Oxford: Princeton University Press, 2006. pp. 126-164.

${ }^{24}$ In Is democracy possible here? Principles for a new political debate. pp. 126-164.

${ }^{25}$ CARBOnELL, Miguel. Silenciar al disidente. La Suprema Corte del México contra la libertad de expresión. Isonomia, n. 24, abril de 2006.
} 
Mas agora o povo participa no pano de fundo como ator da história. Os direitos humanos e dos cidadãos é base normativa para tanto. As autoridades e regimes ditadores reprimem esses direitos; os direitos constitucionais exercidos são ao contrário - uma condição necessária para a Democracia sob o aspecto institucional e procedimental. Apenas uma condição "necessária”, ou seja, não podem simplesmente substituir por completo a Democracia. Entretanto, qualquer Democracia viva está apoiada em direitos constitucionais: liberdade de informação e de opinião, liberdade dos sindicatos e de suas atividades, liberdade dos partidos políticos, liberdade de reunião, demonstração e de associação, direito de escolha livre e imediata, etc."26

Nesse diapasão, parte da construção desta "democracia viva" se faz com o incentivo à criação de novos jornais ${ }^{27}$; a abertura de novas rádios (principalmente as comunitárias); a disponibilização de novos canais abertos de televisão, dentre tantos outros instrumentos de divulgação de idéias e de fomento ao debate.

Segundo Paulo BONAVIDES, "somente por via das lutas constitucionais e dos combates da palavra irradiada de todas as tribunas e de todos os meios de expressão, logrará o povo furar a espessa nuvem que encobre e bloqueia de sombras e trevas a liberdade e a democracia." 28

O resguardo pela livre circulação de idéias implica na luta pela consolidação do regime democrático e pelo aperfeiçoamento das instituições, proporcionando, dessa forma, ao titular absoluto do regime (o povo) a participação na vida pública e a aprovação da condução dos interesses do Estado e da sociedade. Daí porque se faz necessária a intransigente defesa do direito à informação para a construção de uma plena democracia.

\section{REFERÊNCIAS}

AGUINALGA, Enrique de. ?Información veraz?, estúdios sobre el mensage periodístico, n. 4, Madrid: Servicio Publicaciones UCM. pp. 123-133.

ALEXY, Robert; [et alli]. A democracia e os direitos do homem. A democracia. Org. Robert Danton e Olivier Duhamel. Trad. Clóvis Marques. Rio de Janeiro: Record, 2001.

ALMAZÁN, Jaime. Derecho a la Información y Derechos Humanos. Acessível em: http://www.itaipem.org.mx/work/resources/LocalContent/379/3/X\%20mesa\%20Derecho\% 20info\%20jaime\%20almazan\%20ok.doc

Capturado em 02.07.2007 às $10 \mathrm{~h} 47 \mathrm{~min}$.

\footnotetext{
${ }^{26}$ MÜLLER, Friederich. Democracia e República. In Rev. Jur., Brasília, v. 7, n. 77, p. 01-07, fev./mar. 2006. p. 6. Acessível em:

http://www.planalto.gov.br/ccivil_03/revista/Rev_77/artigos/PDF/FriederichM\%FCller_Rev77.pdf.

Capturado em 05 de outubro de 2008 às 13 h26min.

${ }^{27}$ Com relação à importância dos jornais, convém destacar o pensamento de Miguel REALE que pouco antes de falecer asseverou que "à plenitude das formas democráticas corresponde uma multiplicidade de textos do jornal, com a pregação distante de idéias e programas.” Artigo publicado no jornal O Estado de São Paulo de 24 de março de 2006.

${ }^{28}$ BONAVIDES, Paulo. Teoria Constitucional da Democracia Participativa - por um Direito Constitucional de luta e resistência; por uma nova hermenêutica; por uma repolitização da legitimidade. 2. ed., São Paulo; Malheiros Editores, 2003. p. 48.
} 
BRASIL. SUPREMO TRIBUNAL FEDERAL. Indeferimento de pedido de reclamação. Petição n. 3486. Partes: Celso Marques Araújo; Roberto Civita; Marcelo Carneiro e Diogo Mainardi. Relator: Ministro Celso de Mello. 22.08.2005.

BONAVIDES, Paulo. Ciência Política. 3. ed., Rio de Janeiro: Forense, 1976. p. 319.

CARDOSO, Fernando Henrique. A democracia necessária. 3. ed. Campinas: Papirus, 1985.

CARBONELL, Miguel. Silenciar al disidente. La Suprema Corte del México contra la libertad de expresión. Isonomia, n. 24, abril de 2006.

CARVALHO, Luiz Gustavo Grandinetti de. Liberdade de informação e o direito difuso à informação verdadeira. 2. ed. São Paulo: Renovar, 2003.

CASTRO, Carlos Roberto Siqueira. A Constituição aberta e os direitos fundamentais - ensaio sobre o constitucionalismo pós-moderno e comunitário. Rio de Janeiro: Forense, 2005.

DALLARI, Dalmo de Abreu. Elementos de teoria geral do Estado. 26. ed. São Paulo: Saraiva, 2007.

DWORKIN, Ronald. Is democracy possible here? Principles for a new political debate. Princeton and Oxford: Princeton University Press, 2006. pp. 126-164.

GERBNER, George. Os meios de comunicação de massa e a teoria da comunicação humana. In Teoria da comunicação humana. Org.: Frank E. X. Dance. São Paulo: Editora Cultrix, 1967.

HABERMAS, Jürgen. O preço da notícia. Caderno “+MAIS” do Jornal Folha de São Paulo. Domingo, 27 de maio de 2007. tradução ficou a cargo de Samuel Titan Jr.

HESSE, Konrad. Elementos de Direito Constitucional da República Federal da Alemanha (Grundzüge des Verfassungsrechts der Bundesrepublik Deutschland). Tradução de Luís Afonso Heck. Porto Alegre: Sérgio Fabris, 1998.

LOMBARTE, A. Rallo. Pluralismo político e información. Claves de Razón Práctica, n. 96, 1999.

MACHADO, Jónatas E. M. Liberdade de expressão - dimensões constitucionais da esfera pública no sistema social. Coimbra: Coimbra Editora, 2002.

MELO, José Marques. Teoria da comunicação: paradigmas latino-americanos. Petrópolis: Editora Vozes, 1998.

MÜLLER, Friedrich. Democracia e República. Revista Jurídica/ Presidência da República. v. 7, n. 77 - Fevereiro/Março - 2006. Acessível em:

http://www.presidencia.gov.br/ccivil_03/revista/Rev_77/artigos/Muller-rev77.htm

NINO, Carlos Santiago. La Constitucíon de la Democracia Deliberativa. 1. ed, 1 reimp. Barcelona: Gedisa Editorial, 2003.

ROSENSTOCK-HUESSY, Eugen. A origem da linguagem. Trad. Pedro Sette Câmara [et alli]. Rio de Janeiro: Record, 2002. 